\title{
Developing community pediatric care
}

\author{
Martin A. Koyle, MD, MSc
}

Department of Surgery, University of Toronto, Section of Pediatric Urology, The Hospital for Sick Children, Toronto, ON, Canada

Cite as: Can Urol Assoc J 2017;11 (1-2Suppl1):S96. http://dx.doi.org/10.5489/cuaj.4344

See related article on page $\$ 93$.

$\longrightarrow$ anada is geographically a large area, where historically, subspecialty care, especially pediatric urology, has been relegated to tertiary centres. Pediatric urology is unique, as the vast majority of cases are performed on otherwise healthy children with low acuity diagnoses that can be cared for electively as day cases. Hence, breadand-butter cases being sent to high-powered tertiary centres is not only a wasteful practice with respect to costs, but clearly not patient-centred. If such care is to be developed in the community, following guidelines, best practices, and assuring optimal age of surgery to maintain quality and safety are essential.

Dr. Papanikolaou has pointed out the importance of engaging stakeholders and developing a team. This has demanded leadership on his part, for which he has received training. Dr. Lee has added the valuable point regarding funding, where reimbursement for pediatric cases is universally poor, necessitating alternate funding plans in many instances for full-time academic pediatric urologists and making pediatric care in the community less attractive.

I have been perplexed with the arbitrary age cutoffs for which local community anesthesiologists seem comfortable providing elective care in our community. The age of $>1$ year is what they consistently feel is appropriate for safe anesthesia in community care; however, numerous recommendations have suggested that for two of our most common surgical diagnoses, hypospadias and orchidopexy, ideally repair should be attempted within the first year of life. This underscores the importance of team, not just the pediatric urologist being comfortable in providing age-appropriate care.

The question is, in the long-term, is what is the best way to train residents adequately if they are to develop core competencies in pediatric urology to keep care local? Is pediatric urology becoming so unique and foreign that we must develop hybrid adult/pediatric practices after formal fellowship training in pediatric urology? With reimbursement issues, will this be tenable for the infrequent provider of subspecialty care, given risk vs. benefit? The fact that these two authors maintain integrated relationships with their provincial tertiary pediatric urology faculty/centres provides unique opportunities for academic growth and the ability to partner in the care of more complex patients.

Competing interests: Dr. Koyle has been an advisor for Duchesnay.

This paper has been peer-reviewed.

Correspondence: Dr. Martin A. Koyle, Department of Surgery, University of Toronto, Section of Pediatric Urology, The Hospital for Sick Children, Toronto, ON, Canada; martin.koyle@sickkids.ca 